\title{
Cancer incidence in a cohort of Swedish sewage workers: extended follow up
}

\author{
Lennart Friis, Zoli Mikoczy, Lars Hagmar, Christer Edling
}

\begin{abstract}
Objectives-To study the cancer incidence in a cohort of Swedish sewage workers. An increased incidence of cancer of the stomach, the kidney and the nervous system in this cohort was previously reported. This new analysis reports on 9 more years of follow up.

Methods-The study is an analysis of a cohort of all 711 employees at 17 Swedish sewage plants employed for at least for 1 year during the years 1965-86. Assessment of exposures was performed by classification of work tasks. Standardised incidence ratios (SIRs), and $\mathbf{9 5 \%}$ confidence intervals $(95 \% \mathrm{CIs})$ were calculated.

Results-The total cancer incidence was not significantly increased (SIR=1.2, 95\% CI 0.92 to 1.5 ) but the incidence of prostate cancer was $(\mathrm{SIR}=1.6,95 \%$ CI 1.0 to 2.5), and based on two cases only, there seemed to be a significant increase of cancer of the nose and the nasal sinuses (SIR=12, 95\% CI 1.5 to 44$)$. The incidence of stomach cancer was also increased (SIR=2.3, 95\% CI 0.99 to 4.5). There was no relation between cancer incidence and level of sewage exposure.

Conclusions-Sewage workers did not have an increased risk of cancer, and the increased risk estimates for some specific cancer sites were not conclusive.

(Occup Environ Med 1999;56:672-673)
\end{abstract}

Keywords: cancer; epidemiology; sewage workers

Department of Medical Sciences, Occupational and Environmental Medicine, University Hospital, Uppsala, Sweden

L Friis

C Edling

Department of Occupational and Environmental Medicine, University

Hospital, Lund, Sweden

Z Mikoczy

L Hagmar

Correspondence to: Dr Lennart Friis, Department of Medical Sciences, Occupational and Environmental Medicine, University Hospital, S-751 85 Uppsala, Sweden.

Telephone 0046186636 46; fax 004618519978 ; email

Lennart.Friis@occmed.uu.se

Accepted 10 June 1999
Sewage workers are exposed to a wide variety of materials including mutagenic and carcinogenic substances. ${ }^{1-3}$ There are several reports on workers exposed to sewage that indicate an increased risk of cancer at various sites: larynx ${ }^{4}$; liver ${ }^{4}$; stomach $^{48}$; urinary organs ${ }^{4}{ }^{9}$; and lymphopoietic system. ${ }^{5}$ In 1993 we reported the results from a retrospective analysis of a cohort of Swedish sewage workers. ${ }^{10}$ The incidence of all cancers did not differ from that of the general population, but there were numerical increases in cancer of the stomach, the kidney, and the nervous system. This present report accounts for an additional 9 years of follow up and a roughly doubled number of tumours in the cohort.

\section{Subjects and methods}

The cohort was formed of all sewage workers who had worked for $\geqslant 1$ year during the period 1965-86 at the municipal sewage plants in 17 small and medium sized cities in central and southern Sweden. Seven hundred and twelve workers ( 657 men and 55 women) were identified from employment records. The median age at the start of observation was 36 years (range 16-64), and the median duration of employment at the start of observation was 11 years (range 1-49). Vital status was determined on 31 December 1995. One person with a missing national identification number was excluded, one person had emigrated, 130 had died, and 580 were still alive.

For each worker the duration of employment and main work tasks were noted. Also employment before 1965 was noted and accounted for in the analyses with an induction latency period. On the basis of a qualitative exposure classification of the work tasks, four exposure classes were identified in order of increasing exposure: laboratory work, work in the sewage processing plant, sludge pipe flushing or exhaustion, and work at sewage pump stations. Subjects with employment periods with different exposure levels were allocated to their highest exposure class.

Information on tumours diagnosed from 1965 to 1994 and coded according to the seventh revision of the international classification of diseases (ICD-7), was obtained from the Swedish Cancer Register. Expected incidences of cancer for the period 1965-94 were calculated with national incidences specific for calendar year, site, sex, and 5 year age groups. The date of death, a second tumour diagnosis, or emigration were used as individual end points, whichever occurred first.

Cause specific standardised incidence ratios (SIRs) were calculated in separate analyses for 0,10 , and 20 years induction latency periods from the start of exposure until the start of contribution to the person-years under risk. The corresponding 95\% confidence intervals (95\% CIs) were calculated according to the Poisson distribution, or to the normal distribution when the expected values were $>15$. The term "significant" is taken to indicate that the $95 \%$ CI of the risk estimate does not include 1 .

\section{Results}

There were only three cancers among the women sewage workers, one each for mouth, breast, and thyroid. The site and sex specific risk estimates for the men are shown in the table. The total number of cancers did not differ from expected (SIR 1.2, 95\% CI 0.92 to 1.5 ) but the incidence of prostate cancer was significantly higher than expected; 21 versus 13 expected (SIR 1.6, 95\% CI 1.0 to 2.5). Based on two cases only, there seemed to be a significant increase in cancer of the nose and the nasal sinuses (SIR 12, 95\% CI 1.5 to 44 ). The increased incidence of stomach cancer almost reached conventional levels of significance (SIR 2.3, $95 \%$ CI 0.99 to 4.5 ) but the incidence of cancer of the kidney and the nervous system, the two other sites discussed in our previous report, were not significantly increased. 
Site specific cancer incidence (ICD-7) of male Swedish sewage workers 1965-94

\begin{tabular}{|c|c|c|c|c|c|c|c|c|c|c|c|c|}
\hline & \multicolumn{4}{|c|}{$\begin{array}{l}\text { No induction-latency } 13452 \\
\text { person-years }\end{array}$} & \multicolumn{4}{|c|}{$\begin{array}{l}10 \text { years induction-latency } 7756 \\
\text { person-years }\end{array}$} & \multicolumn{4}{|c|}{$\begin{array}{l}20 \text { years induction-latency } 2907 \\
\text { person-years }\end{array}$} \\
\hline & $O$ & $E$ & $S I R$ & $95 \% C I$ & $O$ & $E$ & SIR & $95 \% C I$ & $O$ & $E$ & SIR & $95 \% C I$ \\
\hline All sites (140-209) & 77 & 66 & 1.2 & 0.92 to 1.5 & 65 & 55 & 1.2 & 0.91 to 1.5 & 43 & 32 & 1.3 & 0.98 to 1.8 \\
\hline $\operatorname{Lip}(140)$ & 1 & 0.59 & 1.7 & 0.04 to 9.4 & 1 & 0.47 & 2.1 & 0.05 to 12 & 1 & 0.26 & 3.9 & 0.10 to 22 \\
\hline Mouth $(141,143,144)$ & 1 & 0.66 & 1.5 & 0.04 to 8.4 & 1 & 0.53 & 1.9 & 0.05 to 10 & - & 0.28 & 0 & 0 to 13 \\
\hline Salivary glands (142) & 1 & 0.19 & 5.3 & 0.13 to 29 & 1 & 0.14 & 7.0 & 0.18 to 39 & 1 & 0.07 & 14 & 0.34 to 76 \\
\hline Pharynx (145-148) & 1 & 0.56 & 1.8 & 0.05 to 10 & 1 & 0.45 & 2.2 & 0.06 to 12 & 1 & 0.23 & 4.4 & 0.11 to 24 \\
\hline Oesophagus (150) & 2 & 0.86 & 2.3 & 0.28 to 8.4 & 1 & 0.74 & 1.4 & 0.03 to 7.6 & 1 & 0.42 & 2.4 & 0.06 to 13 \\
\hline Stomach (151) & 8 & 3.5 & 2.3 & 0.99 to 4.5 & 6 & 2.9 & 2.1 & 0.77 to 4.6 & 2 & 1.7 & 1.2 & 0.15 to 4.3 \\
\hline Colon (153) & 2 & 4.6 & 0.43 & 0.05 to 1.6 & 2 & 3.9 & 0.51 & 0.06 to 1.8 & 2 & 2.4 & 0.85 & 0.10 to 3.1 \\
\hline Rectum and anus (154) & 4 & 3.2 & 1.3 & 0.34 to 3.2 & 4 & 2.7 & 1.5 & 0.41 to 3.8 & 3 & 1.6 & 1.9 & 0.40 to 5.6 \\
\hline Pancreas (157) & 4 & 2.1 & 1.9 & 0.51 to 4.8 & 3 & 1.8 & 1.7 & 0.35 to 5.0 & 2 & 0.99 & 2.0 & 0.25 to 7.3 \\
\hline Nose and sinuses (160) & 2 & 0.17 & 12 & 1.5 to 44 & 1 & 0.13 & 7.7 & 0.19 to 43 & 1 & 0.07 & 14 & 0.35 to 78 \\
\hline Trachea, bronchi, and lungs (162.0-1) & 7 & 7.1 & 0.99 & 0.40 to 2.0 & 6 & 5.9 & 1.0 & 0.37 to 2.2 & 4 & 3.3 & 1.2 & 0.33 to 3.1 \\
\hline Prostate (177) & 21 & 13 & 1.6 & 1.0 to 2.5 & 18 & 12 & 1.5 & 0.89 to 2.4 & 15 & 8.0 & 1.9 & 1.0 to 3.1 \\
\hline Renal parenchyma (180.0) & 3 & 2.4 & 1.2 & 0.26 to 3.7 & 2 & 1.9 & 1.1 & 0.13 to 3.8 & 1 & 1.0 & 1.0 & 0.03 to 5.6 \\
\hline Urinary organs (excluding kidney, 181) & 3 & 4.8 & 0.63 & 0.13 to 1.8 & 3 & 4.1 & 0.74 & 0.15 to 2.2 & 1 & 2.4 & 0.42 & 0.01 to 2.3 \\
\hline Malignant melanoma (190) & 3 & 2.4 & 1.3 & 0.26 to 3.7 & 2 & 1.8 & 1.1 & 0.13 to 4.0 & - & 0.88 & 0 & 0 to 4.2 \\
\hline Skin (excluding melanoma, 191) & 2 & 2.5 & 0.79 & 0.10 to 2.8 & 2 & 2.3 & 0.88 & 0.11 to 3.2 & 1 & 1.5 & 0.66 & 0.02 to 3.7 \\
\hline Nervous system (193) & 4 & 2.3 & 1.8 & 0.48 to 4.5 & 3 & 1.6 & 1.8 & 0.37 to 5.3 & 2 & 0.78 & 2.6 & 0.31 to 9.3 \\
\hline Endocrine glands (195) & 1 & 0.92 & 1.1 & 0.03 to 6.1 & 1 & 0.68 & 1.5 & 0.04 to 8.2 & - & 0.32 & 0 & 0 to 12 \\
\hline Multiple myeloma (203) & 2 & 1.0 & 2.0 & 0.24 to 7.1 & 2 & 0.85 & 2.4 & 0.28 to 8.5 & 2 & 0.49 & 4.1 & 0.49 to 15 \\
\hline Polycythemia vera (208) & 1 & 0.23 & 4.4 & 0.11 to 25 & 1 & 0.18 & 5.7 & 0.14 to 32 & 1 & 0.09 & 11 & 0.28 to 61 \\
\hline
\end{tabular}

$\mathrm{O}=$ observed number of cancers; $\mathrm{E}=$ expected number of cancers.

There was no significant increase in the incidence of all cancers combined when accounting for 0,10 , and 20 years induction latency periods, respectively, counted from the beginning of the first exposure period. The risk of prostate cancer increased slightly when the 20 years induction latency was accounted for (SIR $1.9,95 \%$ CI 1.0 to 3.1 ). The risk estimates for all cancers were not related to exposure in any consistent fashion and the numbers of site specific diagnoses were generally too small for meaningful analyses of exposure-response relations.

\section{Discussion}

Our finding of no increased risk for total cancer among the sewage workers was consistent with other studies. ${ }^{4-6}$ Compared with our previous report, the increased incidence of some specific cancers was reduced whereas the increase of prostate cancer was a new observation.

Prevailing geographical differences in cancer incidence and the use of national rates as the reference may cause misinterpretation of the results of this study. Our cohort was collected from small municipalities in Sweden not including the three largest cities. These three cities differ from the rest of the country in some specific morbidities. If a disease being studied is systematically more incident in the largest cities, the real risk for the cohort could be underestimated. The incidence of lung cancer is substantially higher in the largest cities of Sweden whereas the differences for the other cancers of interest in this study are less pronounced.

The aetiology of prostate cancer is unknown and increased risk of prostate cancer has not been reported previously in sewage workers. Occupational exposure to cadmium has been discussed as a potential prostatic carcinogen, but the results from different studies have been inconsistent. ${ }^{11}$ Municipal sewage sludge may contain cadmium, but the exposure of sewage workers is certain to be much lower than the exposures at which an increased incidence of prostate cancer has been reported.
Among the specific cancers discussed in our previous report, stomach cancer might still warrant some interest because of the remaining numerical increase of incidence and similar results reported by other research groups. ${ }^{4-8}$ However, these reports have been inconclusive and there is no report about exposure to any specific gastric carcinogen among sewage workers.

Despite some reports of carcinogenic and mutagenic exposures among sewage workers, ${ }^{1-3}$ there is no convincing evidence of significant carcinogenic exposures in sewage work in general. We found no consistent trend between cancer risk and exposure level, and the highest numerical risk was in fact among those with the lowest exposure. The observations of increased cancer incidences in this study are most likely to be due to chance, at least they do not indicate any large risk. Our final conclusion was that the Swedish sewage workers studied were not at increased risk for cancer due to their work.

1 Rappaport SM, Richard MG, Hollstein MC, et al. Mutagenic activity in organic wastewater concentrates. Environmental Science and Technology 1979;13:957-61.

2 Scarlett-Kranz JM, Babish JG, Strickland D, et al. Urinary mutagens in municipal sewage workers and water treatment workers. Am $\mathcal{F}$ Epidemiol 1986;124:884-93.

3 Babish JG, Johnson BE, Lisk DJ. Mutagenicity of municipal sewage sludges of American cities. Environmental Science and Technology 1983;17:272-7.

4 Lafleur J, Vena JE. Retrospective cohort mortality study of cancer among sewage plant workers. $\mathrm{Am}$ f Ind Med 1991;19:75-86.

5 Betemps EJ, Buncher CR, Clark CS. Proportional mortality analysis of wastewater treatment system workers by birthplace with comments on amyotrophic lateral sclerosis. f Occup Med 1994;36:31-5.

6 Rapiti E, Sperati A, Fano V, et al. Mortality among municipal workers in garbage handling, waste incinerating and sewage treatment: a retrospective cohort study. Epidemiology 1995;6(suppl 4):S135.

7 Chow W-H, McLaughlin JK, Malker HSR, et al. Occupation and stomach cancer in a cohort of Swedish men. Am $\mathcal{F}$ Ind Med 1994;26:11-20.

8 Cocco P, Ward MH, Dosemeci M. Occupational risk factors for cancer of the gastric cardia. F Occup Environ Med 1998; 40:855-61.

9 Sorahan T, Hamilton L, Wallace DMA, et al. Occupational urothelial tumours: a regional case-control study. Br f Urol 1998;82:25-32.

10 Friis L, Edling C, Hagmar L. Mortality and incidence of cancer among sewage workers: a retrospective cohort study. Br f Ind Med 1993;50:653-7.

11 Järup L, Nordberg G. Cancer. In: Järup L, Berglund M, Elinder CG, et al, eds. Health effects of cadmium exposure: a review of the literature and a risk estimate. Scand $\mathcal{F}$ Work Environ Health 1998;24(suppl 1):34-6. 